\title{
Estrategias para el abordaje de caries dental en preescolares.
}

\section{Strategies for the approach of dental caries in preschool children.}

\author{
Abigail Sanchez-Vilchez ${ }^{1, a}$, Kamila Sihuay-Torres ${ }^{2, b, c}$
}

\section{Señor Editor:}

Tras la lectura del artículo "Caries dental y sus consecuencias clínicas relacionadas al impacto de la calidad de vida de preescolares de una escuela estatal”, de Liz Morales y Walter Gómez (1), refiriendo aspectos puntuales sobre la caries, las alteraciones a nivel funcional, estético y psicosocial, y las consecuencias clínicas que van a ocasionar durante el tiempo. A pesar del innegable interés que los hallazgos de este estudio representan para la práctica clínica, no reconocimos, dentro de las recomendaciones de los autores, una estrategia para poder abordar las caries en preescolares.

Consideramos, al respecto, que la higiene bucal no es un actuar simple. La falta de atención y el poco conocimiento de la educación oral, son factores que alteran el interés por la salud bucal creando, directa o indirectamente, ideas poco saludables en los niños y familiares. Por lo cual hemos redactado esta carta con el objetivo de sintetizar algunas estrategias y recomendaciones para futuras intervenciones en esta población afectada.

En vista de la alta prevalencia de caries dental a temprana edad, se recomienda insistir en el cepillado después del consumo de alimentos en especial antes de ir a dormir (2). El cepillado debe ser con pasta dental fluorada (> 1000 ppm de flúor) y uso de hilo dental (3). En el colegio, se debe fomentar el cepillado después de la lonchera por lo que es importante capacitar y concientizar a las maestras y auxiliares para un adecuado acompañamiento a los niños.

Está demostrado que el consumo frecuente de azúcares extrínsecos produce el progreso de la caries dental ya que aumenta la porosidad de la placa dental, los niveles de Streptococcus mutans y mantiene un pH salival ácido $(4,5)$. Por este motivo es necesario tener un control de los alimentos que llevan los preescolares en sus loncheras, así como educar y concientizar a los padres en este tema.

Algunos estudios han encontrado asociación entre el bajo nivel socioeconómico y educativo de los padres, y la alta prevalencia de caries dental (6). Por lo que se recomienda conocer estos aspectos de la comunidad antes de realizar una intervención educativa.

Concluimos que es muy importante realizar intervenciones preventivas de salud bucal en centros educativos de preescolares para reducir la alta prevalencia de caries dental. Cabe resaltar que esta acción debe ser un trabajo en equipo, entre el odontólogo, las maestras, auxiliares y padres de 
familia; todos comprometidos en cumplir el objetivo de cambiar hábitos para reducir este problema de salud pública.

Conflicto de intereses: Los autores declaran no tener conflicto de intereses.

Fuentes de financiamiento: Financiado por los autores.

Responsabilidades éticas: Se declaran las responsabilidades éticas y se afirma el no infringir los principios internacionales de bioética.

Derecho a la privacidad y consentimiento informado: Este estudio no usó consentimiento informado.

Reconocimiento de autoría: Todos los autores contribuyeron igualmente al desarrollo de este estudio.

\section{Correspondencia:}

Abigail Thamara Sanchez Vilchez.

Correo electrónico: thamarita092016@gmail.com

\section{REFERENCIAS BIBLIOGRÁFICAS}

1. Morales L, Gómez W. Caries dental y sus consecuencias clínicas relacionadas al impacto en la calidad de vida de preescolares de una escuela estatal. Rev Estomatol Herediana. 2019;29(1):17-29.

2. Soria A, Molina N, Rodríguez R. Hábitos de higiene bucal y su influencia sobre la frecuencia de caries dental. Acta Pediatr Mex. 2008;29(1):21-24.

3. Casals E. Hábitos de higiene oral en la población escolar y adulta española. RCOE. 2005;10(4):389-401.

4. Flores M, Montenegro B. Relación entre la frecuencia diaria de consumo de azúcares extrínsecos y la prevalencia de caries dental. Rev Estomatol Herediana. 2005; 15(1):36-39.

5. Miyazaki H, Morimoto M. Changes in caries prevalence in Japan. Eur J Oral Sci. 1996:452-58.

6. Mattos A, Melgar A. Riesgo de caries dental. Rev Estomatol Herediana. 2004; 14(1-2):101-106. 